\title{
SLEEP AWAKE AWARE ROUTING PROTOCOL FOR HETEROGENEOUS SENSOR NETWORK
}

\author{
Parvati $^{1}$, Kalpana Chikatwar ${ }^{2}$ \\ ${ }^{I}$ M.Tech Scholar, BKIT Bhalki \\ parvatiswamy18@gmail.com \\ ${ }^{2}$ Associate professor, ECE Department, BKIT Bhalki \\ raghojikalpana@gmail.com
}

\begin{abstract}
The assembly algorithm which is a sort of the core technology applied to decrease the energy expenditure. This algorithm is able to increase the portability plus age of the system. The protocols using this type of algorithm should be designed for the feature of heterogeneous nets. Hence proposed the sleep awake aware (SAA) routing protocol for heterogeneous WSN. And here we enhanced the cluster head selection technique for heterogeneous WSN by introducing the pairing concept. The result indicates the energy can be conserve better as compared to others.
\end{abstract}

Keywords: WSN, Heterogeneous Sensor Network, Force Efficiency, Routing Protocol.

\section{PREFACE}

As we know at present due to the development of technology WSNs are rising quickly the WSN can be described as a set of movable or standing motes these are capable of interact with every one for sending data more powerfully and equivalent. The network which is created by a huge integer of sensor nodes where each is outfitted through the sensor to identify physical phenomena such as brightness, high temperature, pressure, etc is referred as a wireless sensor network. WSNs are considered as a innovatory information collecting way to make the information and communication system which will highly increases the reliability and efficiency of infrastructure systems. The life times of the battery used in systems are limited. So it is difficult to put back in the network. Due to this, age factor can be taken as a major goal of the arrangement. By keeping the main goal in mind many routing protocols were proposed for WSN.

And they are three types, first one is flat second is hierarchical and last is location based protocol. Among these three the power competence offered by second type is highest. To enhance the age and diminish the wastage or power, logically, combining the smart dust into clusters this is usually accepted by the scientist people. In return, routing hierarchy and message collection protocols means organizing the mass based on sensor nodes in order to achieve significant savings in energy. The data synthesis and reduction is done by chief of the cluster in hierarchy structure of the network.

At our proposed model, we investigated the performance of the SAA (sleep awake aware) protocol and saved the energy with the help of coupling concept for network having heterogeneous nodes. Here the destination node is situated away from the detection area, where the every head of the cluster has to be send the sensed information which is received by its member nodes.

\section{PROPOSED MODEL}

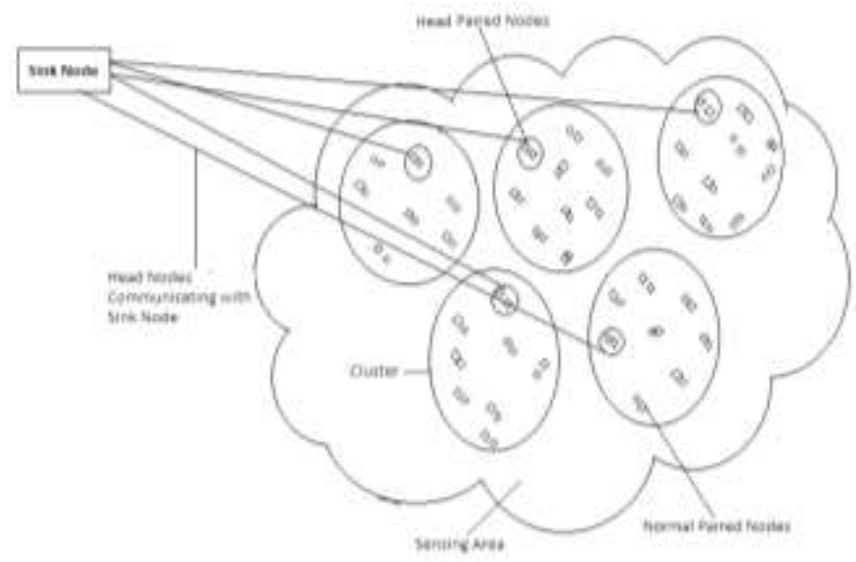

Fig. 2.1.Proposed network model

In this proposed model the system is prearranged into grouping manner. Different power nodes are deployed in the network. Here starting energy of every node is not same. This is called as heterogeneity factor. In which a few are outfitted with extra energy compared to regular nodes. This nodes arrangement is aimlessly or physically based on its application. at first senor nodes compute their position with the help of GPS.The place, its type and identification number is sent by the nodes to sink node. The bunch head is selected after placing of heterogeneous nodes. The $\mathrm{CH}$ broadcast the pairing information to the net. The smart dust come to know about that with whom it has been combined after receiving the pairing information from the cluster head. According to the proposed model nodes set off into sleeping 
and wide awake form during one way communication interval. Firstly nodes which are at a match up goes to wake up style called as dynamic method, when it is closer to the $\mathrm{CH}$ than the co-worker node. At that time the transmitter and receiver of the joint node is off also its position is in sleepy form. A further communication duration dynamic form node goes to sleep form and vice-versa. The power utilization is diminished because the sleep mode nodes put away their energy by not interacting with the cluster head.

\subsection{CH (Cluster Head) Scheme}

In earlier protocols like LEACH [1], LEACH-C, PEGASIS [2], SEP etc...Group chief is chosen based on threshold value and left over energy of smart dusts. In our planned protocol $\mathrm{CH}$ preferred based on the below factor.

- Higher energy node.

- Node near to the base station.

- Larger area (the node which covers more nodes).

If these above circumstances are assured then that node can be elected as cluster head.

\subsection{Nodes Pairing}

$\mathrm{CH}$ couples the nodes by considering the below factors

- Nodes of same application type.

- Nodes that comes within its sensing range.

Following the finishing of coupling procedure, the $\mathrm{CH}$ sends that coupled information to the system and base station. In the coupled node one node is switch into active mode which is near to the cluster leader and the other node is switch into the sleep mode.

Table 2.1.Performance factors

\begin{tabular}{|l|l|}
\hline Constraints & Value \\
\hline Dimension of network & $(100 \mathrm{~m} \times 100 \mathrm{~m})$ \\
\hline Nodes taken & $(50,60,70,80,90,100)$ \\
\hline Total rounds & 4000 \\
\hline Initial energy & $0.5 \mathrm{j}$ \\
\hline Etx & $50 \mathrm{nj} / \mathrm{bit}$ \\
\hline Erx & $50 \mathrm{nj} / \mathrm{bit}$ \\
\hline Sensor range & $10 \mathrm{~m}$ \\
\hline Cluster range & $20 \mathrm{~m}$ \\
\hline
\end{tabular}

\section{RESULT}

We have simulated the wireless sensor network in Mat Lab environment in $100 \mathrm{~m} \mathrm{X} \mathrm{100m} \mathrm{field.} \mathrm{The} \mathrm{table} 1$ shows the simulation constraints used.

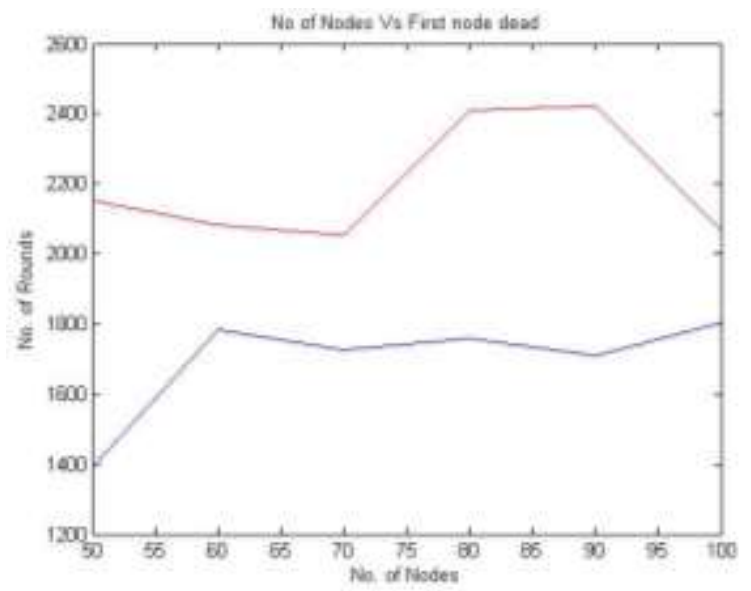

Fig. 2.2. First quiet nodes for selected network

The above figure represents when the first node has dead for homogeneous as well as heterogeneous network. The red line indicates our proposed result which gives better lifespan compare to homogeneous network.

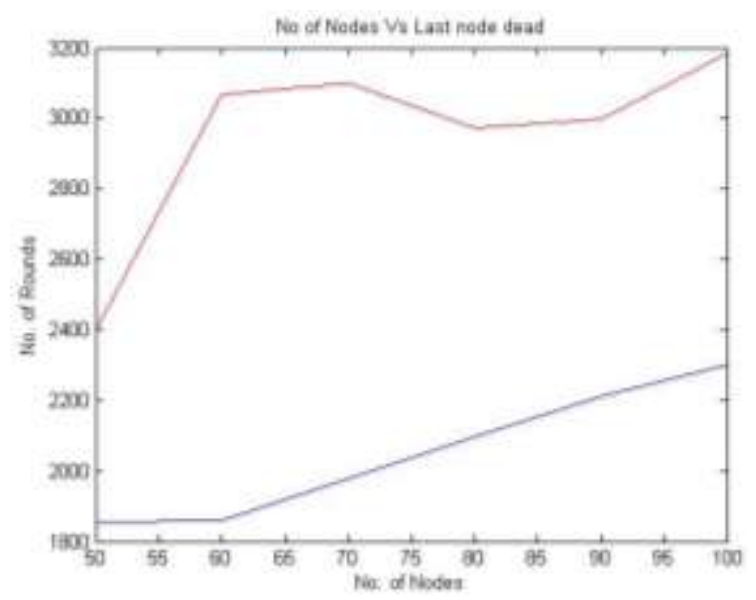

Fig. 2.3. Last departed nodes for proposed model

By observing the diagram -3 we concluded that in heterogeneous network the last node dies around 3000 but in homogeneous the last node dies sooner compare to the proposed scheme.

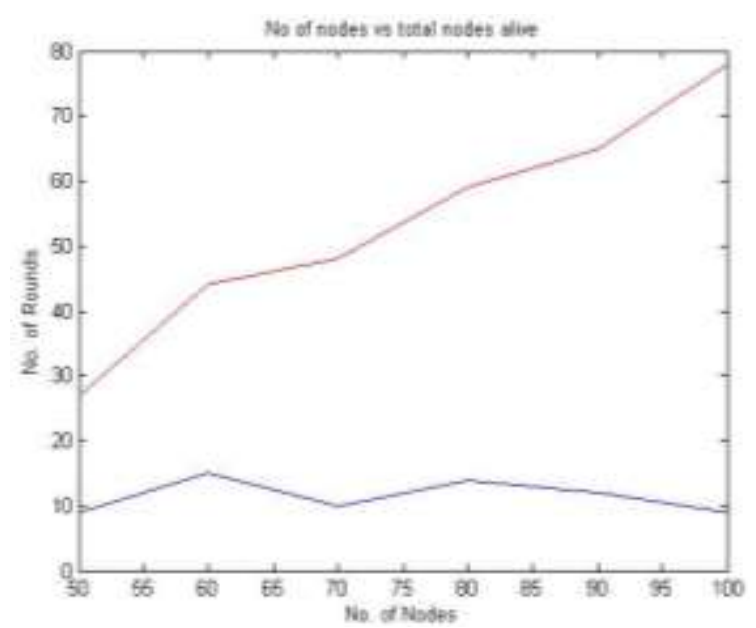

Figure 2.4. Alive nodes for $100 \mathrm{~m} \times 100 \mathrm{~m}$ network with different node 
The graph which is shown above gives number of node vs. total nodes alive for dissimilar nodes. Here we noticed that there is a rapid enhancement of dead cluster members in homogeneous, where as in heterogeneous model nodes dies at constant rate.

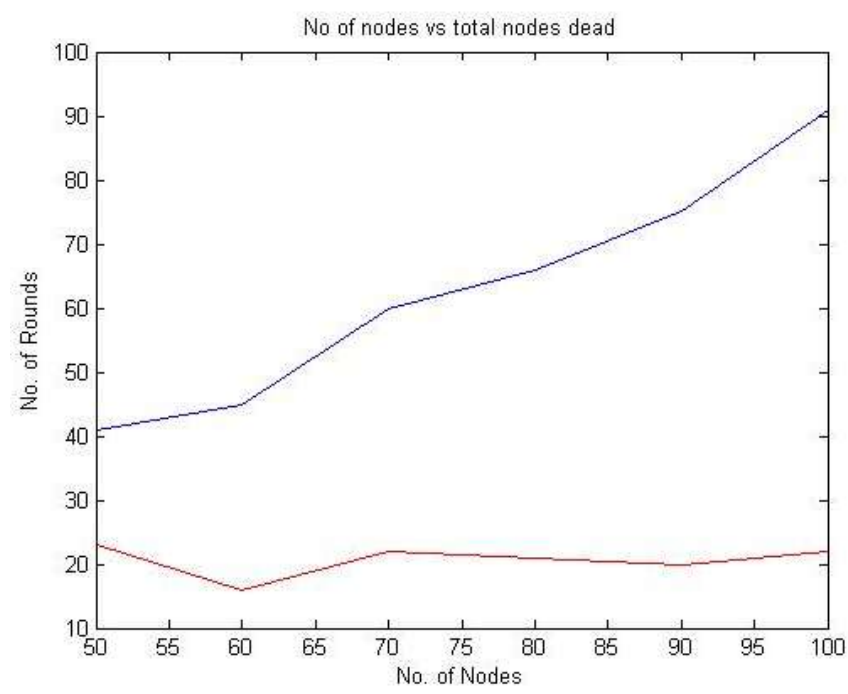

\section{Figure 2.5.Total Dead Nodes For Given Network.}

The picture which is shown above specifies that the nodes death rate goes on increasing in homogeneous network which leads to network failure. Where as in proposed protocol constant death rate can be achieved.

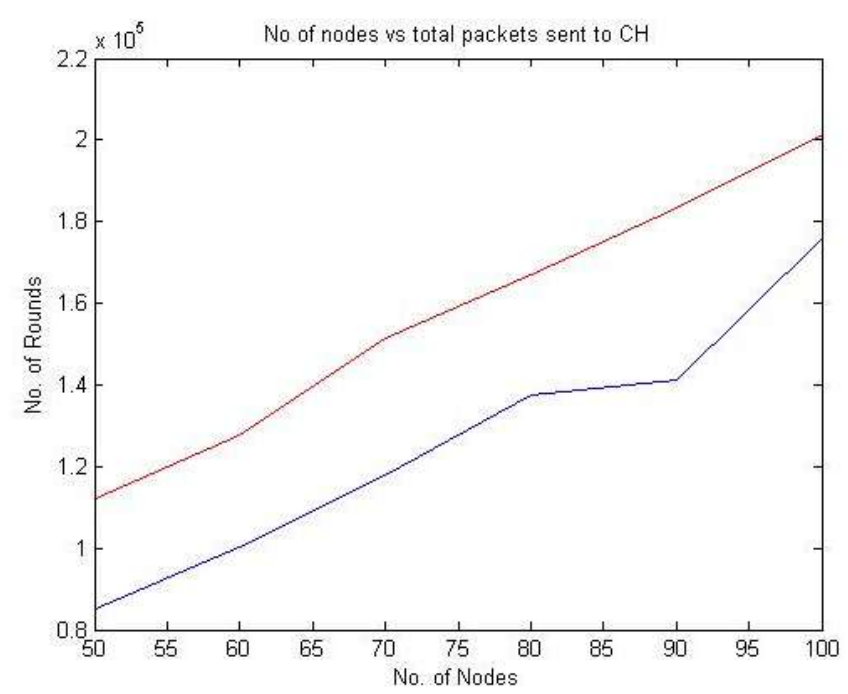

Figure 2.6.Total packets sent to $\mathrm{CH}$ for $100 \mathrm{~m} \times 100 \mathrm{~m}$ network with different nodes

The graphical representation as shown above gives the packets delivered to the head node for both the networks. By seeing that outcome we say that more packets can be transmitted in heterogeneous network than the homogeneous network.

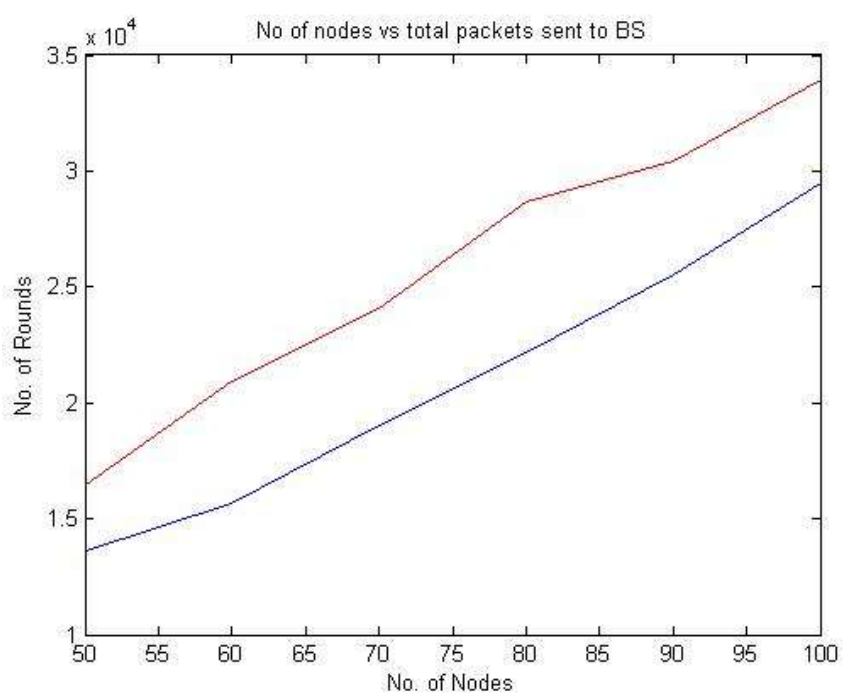

Figure. 2.7. Total packets sent to sink node for the planned model

As we mentioned at figure 6 more number of information can be sent to $\mathrm{CH}$ in our proposed model. Obviously at sink node side also more packets can be transferred which is shown at above graph. So finally we say that our proposed protocol performed superior than others.

\section{CONCLUSION}

Here we proposed sleep awake alert protocol with enhanced $\mathrm{CH}$ (cluster head) selection technique which conserve the power finer than the others. And therefore we got the enhanced network duration. For heterogeneous sensor network our Model effect demonstrates that our proposed protocol achieves recovered performance as match up to other protocols.

\section{REFERENCES}

[1] W. Heinzelman, A. Chandrakasan, and H. Balakrishnan, "Energy-efficient routing protocols for wireless microsensor networks," in Proc. 33rdHawaii Int. Conf. SystemSciences(HICSS), Maui, HI,Jan. 2000.

[2] S. Lindsey and C. S. Raghavendra. PEGASIS: oweref?cient gathering in sensor information systems. In Proceedings of the IEEE Aerospace Conference, March 2002.

[3] X. H. Wu, S. Wang, "Performance comparison of LEACH and LEACHC protocols by NS2," Proceedings of 9th International Symposium on Distributed Computing and Applications to Business, Engineering and Science. Hong Kong, China, pp. 254-258, 2010

[4] G. Smaragdakis, I. Matta, A. Bestavros, SEP: A Stable Election Protocol for clustered heterogeneous wireless sensor networks, in: Second International Workshop on Sensor and Actor Network Protocols and Applications (SANPA 2004), 2004.

[5] L. Qing, Q. Zhu, M. Wang, 'Design of a distributed energy-efficient clustering algorithm for heterogeneous wireless sensor networks". ELSEVIER, Computer Communications 29, 2006, pp 2230- 2237. 
[6] Femi A. Aderohunmu, Jeremiah D. Deng "An Enhanced Stable Election Protocol (SEP) for Clustered Heterogeneous WSN". X. H. Wu, S. Wang, "Performance comparison of LEACH and LEACH-C protocols by NS2," Proceedings of 9th International Symposium on Distributed Computing and Applications to Business, Engineering and Science. Hong Kong,

China, pp. 254-258, 2010

[7] Fan Xiangning1,2 Song Yulin "Improvement on LEACH Protocol of Wireless Sensor Network" International Conference on Sensor Technologies and Applications 2007.

[8] Thiemo Voigt, Hartmut Ritter, Jochen Schiller, Adam Dunkels, and Juan Alonso, ". Solar-aware Clustering in Wireless Sensor Networks", In Proceedings of the Ninth IEEE Symposium on Computers and Communications, June 2004.

[9] Md. Junayed Islam, Md. Muhidul Islam, Md. Nazrul Islam "A-sLEACH: An Advanced Solar Aware Leach Protocol for Energy Efficient Routing in Wireless Sensor Networks" Proceedings of the Sixth International Conference on Networking (ICN'07) 